\title{
Erratum
}

\section{On the Application of a Classical Perturbation Theory to the Theory of Coupled Fields}

\section{Hermann Hartmann and Kyu-Myung Chung}

Theoret. Chim. Acta (Berl.) 47, 147-156 (1978).

On page 149 under the Eq. (5) $N=0$ should read $\sigma=0$.

On page 153 in Eq. (30) $\Omega_{0}=-\mu_{0} \Delta$ should read $\Omega_{0}=-\mu_{0}\left(\Delta-k^{\prime \prime 2}\right)$.

On page 154 in Eq. (32) $\left(-\frac{1}{\mu_{0}} \Lambda^{-1} \delta\left(x-x^{\prime}\right)\right)$ should read $-\Omega_{0}^{-1} \delta\left(x-x^{\prime}\right)$. In the definition of the

Green's function the inverse of the Laplace operator should be replaced by $\Omega_{0}^{-1}$ and the Eq. (33) should read

$$
\mu_{0} G\left(x-x^{\prime}\right)=\left(4 \pi\left|x-x^{\prime}\right|\right)^{-1} e^{i k^{\prime \prime}\left|x-x^{\prime}\right|} .
$$

On page 154 in Eqs. (35), (36) and (37) the position vector $\boldsymbol{x}^{\prime}$ should read $\boldsymbol{x}$.

Received March 22, 1978 